\title{
MORTALIDADE DE MICROEMPRESAS: UM ESTUDO DE CAMPO REALIZADO COM MICROEMPRESÁRIOS DA REGIÃO CENTRO DO ESTADO DO RIO GRANDE DO SUL
}

\section{MORTALITY OF SMALL BUSINESSES: A FIELD STUDY CONDUCTED WITH MICROENTREPRENEURS IN THE CENTER OF THE RIO GRANDE DO SUL STATE}

\author{
Larissa Disconzi Perufo \\ Universidade Federal de Santa Maria (UFSM) \\ Santa Maria, RS, Brasil \\ Email: larissaperufo@hotmail.com \\ Leoni Pentiado Godoy \\ Universidade Federal de Santa Maria (UFSM) \\ Santa Maria, RS, Brasil \\ Email: leoni@smail.ufsm.br
}

\section{RESUMO}

Em virtude da grande participação das microempresas na economia brasileira, e do alto índice de mortalidade destas, o contexto bibliográfico vem assumindo um papel importante neste meio, com o objetivo de compreender e minimizar os principais descuidos que levam o negócio a este patamar. Assim buscou-se através deste estudo identificar as principais causas que levam ao encerramento de microempresas. Para isto, optou-se por uma pesquisa de natureza qualitativa e quantitativa, exploratória e descritiva, realizada através de um estudo de campo. A partir da aplicação do questionário em microempresários da região central do estado do Rio Grande do Sul, os quais fecharam seus negócios com menos de três anos ativos, por diversas situações apresentadas, tornou-se possível a identificação da área de marketing como um campo bastante estratégico e pouco desenvolvido por parte dos entrevistados e adentro deste, 0 indicador considerado como umas das principais causas da mortalidade destas organizações foi a falta de controle dos resultados a partir da utilização das práticas de gestão da área, seguido da não utilização das técnicas de endomarketing.

Palavras-chave: Microempresas.

Empreendedorismo. Mortalidade. Planejamento estratégico. Marketing.

\section{ABSTRACT}

Due to the large participation of microenterprises in the Brazilian economy, and the high mortality rate of these, the bibliographic context has assumed an important role in this environment, with the aim to understand and minimize major oversights that lead the business to this level. So, we sought through this study to identify the main causes leading to the closure of microenterprises. For this, we chose a research nature of quantitative and qualitative, exploratory and descriptive, conducted through a field study. Based on the data collected, it is possible to affirm thar microentrepreneurs in the central region of Rio Grande do Sul, which closed their business with less than three active years for various situations presented, it became possible to identify the area of marketing as a strategic field and underdeveloped by the interviewees and inside this, the indicator regarded as one of the leading causes of mortality of these organizations was the lack of control results from the use of management practices in the area, followed by the non-utilization of endomarketing techniques.

Keywords: Microenterprises. Entrepreneurship.

Mortality. Strategic planning. Marketing.
Data de aprovação: 28 de novembro de 2018. 


\section{INTRODUÇÃO}

A questão da mortalidade de microempresas tornou-se através da evolução histórica das organizações um problema crônico, dessa maneira esta dificuldade aos poucos tem assumido grandes dimensões no contexto bibliográfico. $\mathrm{O}$ ar de inevitabilidade assumido pelos empreendedores, aos poucos foi dando espaço para as reais práticas erroneas, exercidas pelos empreendedores, que levam a extinção do negócio (MACHADO e ESPINHA, 2005).

Segundo o último levantamento do SEBRAE, (2012) o Brasil conta com aproximadamente 6 milhões de microempresas sendo que a Região Sul é responsável por $23,3 \%$ destas. Além disso, a participação na economia brasileira, por estas organizações localizadas no Sul, é expressiva, 20\% do PIB é resultante delas, contribuindo ainda com $11 \%$ das exportações e $40 \%$ da renda total. Sendo assim $60 \%$ dos empregos hoje derivam da existência de micro empreendimentos, ou seja, 60 milhões de brasileiros. Desta maneira o assunto mortalidade deve ser encarado com mais clareza, mergulhando mais a fundo nos fatores que levam estas organizações a não continuarem ativas no mercado.

Contudo em vista dos diversos desafios enfrentados hoje pelos microempreendedores e da representatividade que estas organizações representam para o País. Esta pesquisa tem o intuito e a problemática acerca da extinção precoce de microempresas, partindo do fator planejamento estratégico, que por estudos já realizados foi um dos principais motivos das dificuldades encontradas pelos empreendedores.

Deste modo o objetivo desta pesquisa consiste em apresentar as principais causas, inerentes ao planejamento estratégico, que não permitem às microempresas da Região centro do Estado do RS continuarem suas atividades após a fase de maturidade.

\section{MICROEMPRESAS}

As microempresas (ME) têm participação marcante na economia brasileira. Esta afirmação provém de números expostos por pesquisas realizadas, como publicação do Instituto Brasileiro de Geografia e Estatística - IBGE (2012). Mostrando que as ME ocupam 93,3\% do mercado brasileiro, sendo estas indústrias, construção, comércio e serviços, onde $64,76 \%$ destas empresas atuam sem empregados e o restante trabalha com o auxilio de funcionários (SEBRAE, 2012; GRAPEGGIA et al., 2011).

Outro fator relevante é que em 2011 as MEs foram responsáveis por 15 milhões de empregos formais, mais da metade destes em estabelecimentos privados não agrícolas do país, e por $40 \%$ da massa de salário paga aos trabalhadores destes estabelecimentos (SEBRAE, 2012).

A pesquisa ainda destaca que entre 2000 e 2011, a remuneração média real dos empregados formais nas microempresas cresceu $1,5 \%$ a.a., passando de $R \$ 1.019$, em 2000 , para $R \$ 1.203$, em 2011 . Este resultado foi superior tanto ao crescimento da renda média real de todos os trabalhadores do mercado formal (1,2\% a.a), quanto daqueles alocados nas médias e grandes empresas ( $0,8 \%$ a.a).

Criada em 1996 a Lei $n^{\circ} 9.317$ que instituiu o Sistema Integrado de Pagamentos de Impostos e Contribuições das Microempresas e Empresas de Pequeno Porte, afirma que ME constitui-se de pessoa jurídica com faturamento anual de $\mathrm{R} \$ 240.000,00$. De acordo com o Estatuto da Microempresa e Empresas de Pequeno porte (Lei $n^{\circ}$ 9.841/99), o Decreto $n^{\circ} 5.028$, de 31 de março de 2004, classifica a ME como 
empresa constituída por pessoa jurídica ou firma mercantil individual que tiver receita bruta anual igual ou inferior a $\mathrm{R} \$ 433.755,14$. No Quadro 1 é possível observar as diferentes classificações da Microempresa (CARTILHA SIMPLES NACIONAL, 2008 p. 7; ESTATUTO DA MICROEMPRESA, 2003).

Quadro 1 - Diferentes classificações da microempresa

\begin{tabular}{|c|c|c|}
\hline INSTITUIÇÃO & \multicolumn{2}{|c|}{ MICROEMPRESA } \\
\hline \multirow{2}{*}{$\begin{array}{c}\text { Simples Nacional } \\
e \\
\text { Lei Geral das ME }\end{array}$} & Tipo Jurídico & Faturamento \\
\hline & $\begin{array}{l}\text { Empresário Individual; } \\
\text { Sociedade Empresária (comercial); } \\
\text { Sociedade Simples (civil). }\end{array}$ & $\begin{array}{l}\text { Receita bruta anual igual ou inferior a } \\
R \$ 240.000,00\end{array}$ \\
\hline \multirow{2}{*}{$\begin{array}{l}\text { Estatuto da Microempresa e } \\
\text { Empresas de Pequeno }\end{array}$} & Tipo Jurídico & Faturamento \\
\hline & Pessoa Jurídica ou Mercantil & $\begin{array}{l}\text { Receita bruta anual igual ou inferior a } \\
\mathrm{R} \$ 433.755,14\end{array}$ \\
\hline \multirow{3}{*}{ SEBRAE } & Setor & Quantidade Funcionários \\
\hline & Indústria e Construção Civil & Até 19 empregados \\
\hline & Comércio e Serviços & Até 9 empregados \\
\hline \multirow{2}{*}{ BNDES } & \multicolumn{2}{|c|}{ Faturamento } \\
\hline & \multicolumn{2}{|c|}{ Receita operacional bruta anual ou anualizada inferior ou igual a $R \$ 1.200 .000,00$} \\
\hline
\end{tabular}

Fonte: Elaborado pelos autores baseado em Cartilha simples nacional, 2008 p. 7; estatuto da microempresa (2003); BNDES Carta Circular $n^{\circ} 64$ (2002) e SEBRAE (2012).

Cada instituição tem característica distinta para classificar uma microempresa, o SEBRAE opta por distingui-la através da quantidade de funcionários, enquanto o BNDES pela receita operacional bruta anual (BNDES Carta Circular $n^{\circ}$ 64/2002). Isto se da pelo fato de que cada local interage com a ME de formas diferenciadas, como por exemplo, o SEBRAE, que exerce a função de apoio e incentivo às micro e pequenas empresas, capacitando da melhor maneira os gestores e empreendedores do negócio.

O valor das microempresas na atividade empresarial nacional é observado por diversos autores (KOTESKI, 2004; DE PAULA, 2008; TRINDADE et al., 2010), os quais trazem essas empresas como um dos principais pilares para a sustentação da economia brasileira, pois estas acabam por se sobressaírem como autoras de ocupação e renda no país, além de contribuírem de forma crescente para o aumento do Produto Interno Bruto (PIB) anual. Assim, ainda tendo muita importância e muitos incentivos, até mesmo na própria Constituição Federal de 1988 que define tratamento jurídico diferenciado, as ME se caracterizam como organizações pouco planejadas.

A baixa intensidade de capital, os registros contábeis pouco adequados, a contratação direta de mão de obra, a utilização de mão de obra não qualificada ou pouco qualificada, o baixo investimento em inovação tecnológica, a relação de complementaridade e a subordinação com as empresas de grande porte, a forte presença de proprietários e/ou sócios dos negócios centralizando o poder, a dificuldade de acesso ao crédito e a confusão entre pessoa física e jurídica, tudo isso leva ao problema das ME's, as altas taxas de natalidade e de mortalidade (IBGE 2013). 


\section{O EMPREENDORISMO E O EMPREENDEDOR DA MICROEMPRESA}

O empreendedorismo em larga escala tende a ser descrito como um conjunto de atitudes que inclui: a capacidade para tomar iniciativa; a habilidade de organizar e reorganizar mecanismos sociais e econômicos, a fim de transformar recursos e situações para proveito prático, e a capacidade de aceitar o risco ou o fracasso (FISCHER, NODARI e FEGER, 2008). Atualmente, o enfoque econômico tende a alinhar os empreendedores com as inovações, desta forma o enfoque comportamentalista vem concentrando-se nas características de capacidade e dinamismo do indivíduo empreendedor, fazendo destas ferramentas vitais para o sucesso do empreendimento e consequentemente o desenvolvimento do país.

Vários autores como Ferreira et al. (2012), destacam os motivos que incentivam empreendedores a abrirem seu negócio, que são principalmente a identificação de uma oportunidade, as experiências anteriores e a insatisfação e tempo disposto com o emprego atual. Além de todos estes fatores, os incentivos financeiros e a facilidade com a qual o governo trata a abertura destas empresas a fim de enxergar o desenvolvimento do país, são quesitos positivos na hora da tomada de decisão do investidor.

Contudo Souza e Lopez (2011) consideram que um dos principais problemas nos estudos de empreendedorismo é a definição e a identificação do que é ser empreendedor, pois, indicam que, apesar de muitos estudos, ainda não é possível caracterizar adequadamente empreendedores e, principalmente, proprietários de pequenos negócios. Desta maneira é possível compreender em partes, o porquê de algumas microempresas conseguirem manterem-se vivas no mercado sem nenhum planejamento e/ou inovação.

Fatores que condicionam uma boa gestão das microempresas em torno do planejamento estratégico

Em diversos estudos sobre mortalidade precoce de microempresas o fator planejamento estratégico está sempre elencado como uma das causas principais, segundo Grapeggia et al., (2011); Ferreira et al., (2012); Dutra, (2002) e Bedê, (2004) o fator relacionado ao planejamento é considerado um ponto ideal para o sucesso das microempresas, porém os empreendedores afirmam que, o foco na fase de maturidade das organizações é a questão financeira, ou seja, como eles irão captar os recursos necessários para manter o negócio.

Neste sentido o estudo em questão abordou alguns critérios que auxiliados pelo planejamento estratégico acabam por identificar as melhores oportunidades atuais e otimizam o empreendimento na execução de objetivos futuros (OLIVEIRA, 2002). Na Figura 1 é possível verificar melhor este contexto. 
Figura 1: Modelo de gestão focado em planejamento estratégico

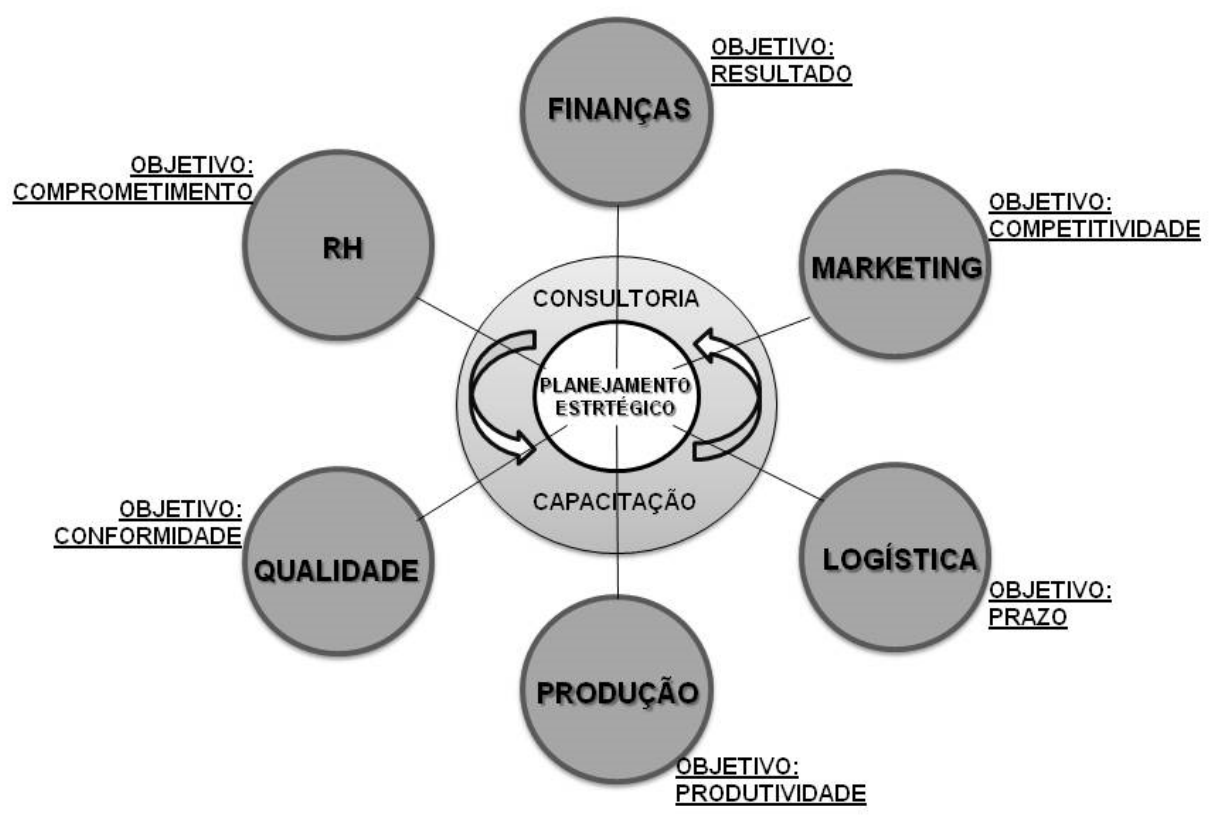

Fonte: Elaborado pelos autores baseado em Wright, Kroll e Parnell (2000); Fenandes e Berton (2006)

Sabe-se que existe uma forte resistência à implantação de um processo de planejamento ao redor da gestão nas microempresas, no entanto é de fundamental importância a inserção do planejamento estratégico no âmbito organizacional.

Esta inclusão é importante no momento em que são necessárias previsões tanto financeira, como de demanda, avaliações das expectativas dos clientes como da qualidade do produto ou serviço oferecido, elaboração de estratégias para a resolução de problemas como para alcançar a máxima contribuição e dedicação de um funcionário, tudo isso em prol do objetivo principal de cada área (BERNARDI, 2011; KPLAN e NORTON, 2004).

De acordo com Thompson Jr e Strickland III (2002) são estas as estratégias funcionais básicas de uma organização. O planejamento e coordenação, destas unidades, estrategicamente, tendem a acrescentar vigor à estratégica principal do negócio, mas antes disso alcançar o objetivo chave de cada área.

As capacidades necessárias para atender à missão da empresa podem ser advindas de qualquer âmbito, por isso executar um planejamento em toda a gestão requer uma metodologia mais aberta e melhor distribuída. O que quer dizer que se deve quebrar o paradigma de ambiente autocrático e familiar da maioria das microempresas e delegar estas funções em nível de consultoria estratégica ou executar uma capacitação continua (BARROS, 2005; WRIGHT, KROLL e PARNELL, 2000; BATISTA, et al., 2012).

\section{MORTALIDADE NAS MICROEMPRESAS}

As elevadas taxas de mortalidade de empresas sempre despertaram o interesse dos pesquisadores em diversas partes do mundo. Segundo indicadores da Serasa Experian (2013), mais de 900 mil empresas abriram as portas no mercado brasileiro no primeiro semestre do ano de 2013. Por outro lado, a pesquisa Sobrevivência das Empresas no Brasil, divulgada pelo Sebrae (2013) revela que a taxa de mortalidade dessas 
empresas chega a $26,4 \%$, ou seja, a cada 12 novas empresas abertas, aproximadamente 3 encerram suas atividades antes de completar 2 anos.

A pesquisa Demografia das Empresas - 2011, divulgada pelo Instituto Brasileiro de Geografia e Estatística - IBGE (2013), apresenta um cenário mais preocupante ainda, esta relata que $48,2 \%$ destas empresas não sobreviverão até os três anos de existência, ou seja, segundo esta pesquisa, praticamente metade das empresas brasileiras encerram suas atividades antes de completarem três anos.

Existe uma relação direta entre o porte das empresas e a taxa de sobrevivência destaca o instituto (IBGE). Enquanto 67,3\% das empresas sem funcionários contratados eram sobreviventes em 2010, a taxa de sobrevivência era de $95,9 \%$ entre as empresas com 10 ou mais pessoas ocupadas. Deste modo reafirmase o alto grau de mortalidade das microempresas.

Assim Dornelas (2005) aponta as principais causas para o insucesso de microempresas sendo para ele primeiramente a falta de planejamento, seguido da deficiência na gestão, políticas de apoio insuficientes, conjuntura econômica e fatores pessoais. No Quadro 2 isto pode ser melhor visualizado, a qual mostra as causas mais frequentes que ocasionam a mortalidade das chamadas starts-up, pequenas empresas dos Estados Unidos país de referência em empreendedorismo.

Quadro 2. Causas de fracasso das starts-ups americanas

\begin{tabular}{|l|c|}
\hline \multicolumn{1}{|c|}{ Fatores } & Percentual \\
\hline Incompetência Gerencial & $45 \%$ \\
\hline Expertise Desbalanceada & $20 \%$ \\
\hline Inexperiência em Gerenciamento & $18 \%$ \\
\hline Inexperiência no Ramo & $9 \%$ \\
\hline Negligência nos Negócios & $3 \%$ \\
\hline Fraudes & $2 \%$ \\
\hline Desastres & $1 \%$ \\
\hline Total & $\mathbf{9 8 \%}$ \\
\hline \multicolumn{2}{|c|}{ Apenas 2\% são fatores desconhecidos } \\
\hline Fonte: Dornelas (2005, 95)
\end{tabular}

Fonte: Dornelas (2005, p. 95)

Como pode ser visto as duas principais causas remetem ao planejamento. Os empreendedores falham em não possuírem uma capacitação gerencial contínua e fazer uso da aplicação dos conceitos gerenciais, além de não se disciplinarem a realizar um planejamento periódico da sua gestão do negócio. Nas empresas que deram certo nos Estados Unidos no estágio de maturidade, seus empreendedores realizaram análises criteriosas em torno de todo o empreendimento antes de colocá-lo no mercado (SHANE, LOCKE e COLLINS, 2003; STEL, CARREE e THURIK, 2005). No Brasil não é diferente há falta de planejamento segundo pesquisas do Sebrae (2012), na Figura 2 é possível observar as principais causas que levam ao fechamento de microempresas brasileiras antes dos 3 anos de existência. 
Figura 2: Principais causas que levaram ao fechamento de microempresas brasileiras

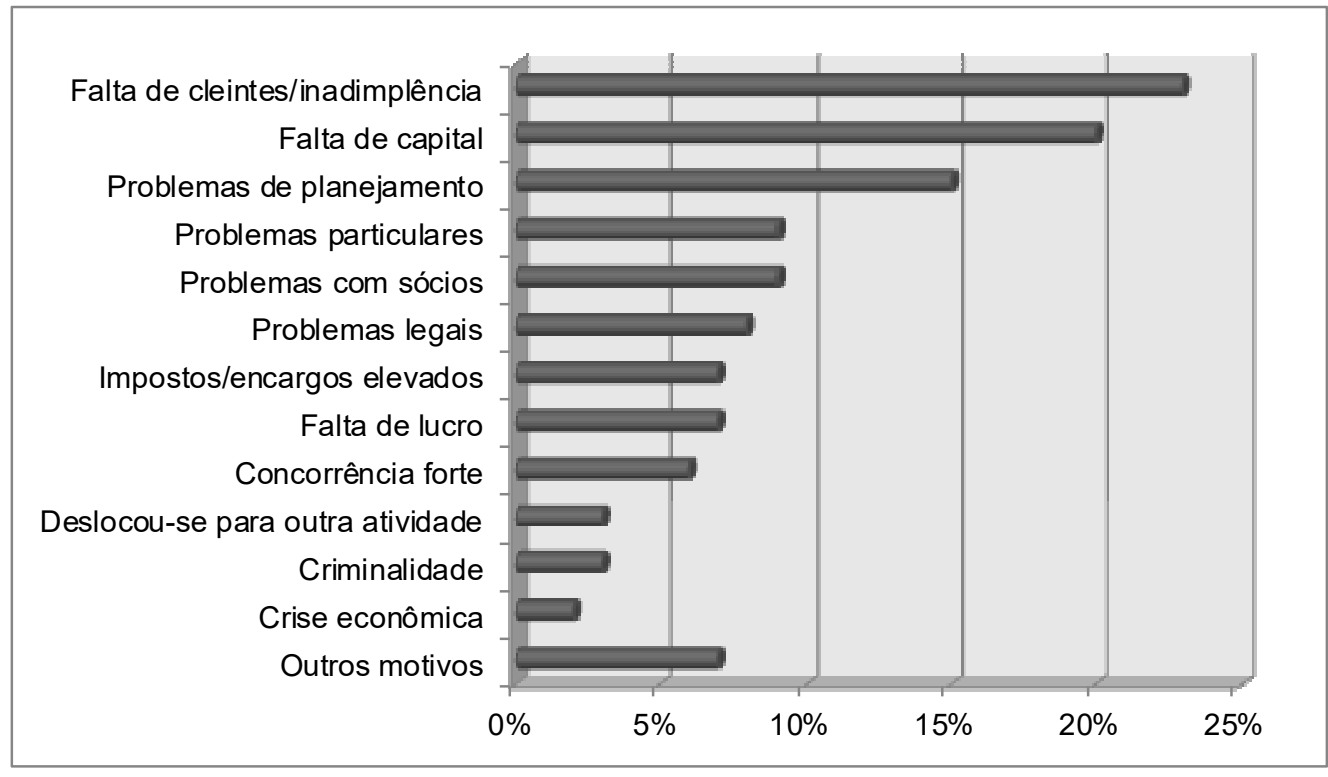

Fonte: Elaborado pelos autores, baseado em Sebrae (2012)

A Figura 2 demonstra que, na visão dos empresários, $65 \%$ dos motivos que levaram ao encerramento das atividades estão relacionados a problemas de gestão das empresas, tais como a falta de clientes e/ou inadimplência $(23 \%)$, falta de capital $(20 \%)$, problemas de planejamento $(15 \%)$ e falta de lucro $(7 \%)$. O que já demonstra uma maior conscientização destes empresários sobre a necessidade de conhecimento e aplicação de técnicas de gestão empresarial.

Cochran (1981) identifica cinco diferentes definições para o conceito de falência. Primeiramente citase a falência formal, são empresas que formalizam o encerramento de suas atividades junto aos órgãos oficiais, para ele existe também o encerramento das atividades com dívidas a credores, sem baixa formal, o encerramento das atividades para evitar perdas e dívidas também sem baixa formal, empresas vendidas ou transformadas em outras atividades e descontinuidade da empresa por qualquer outra razão.

Nesta pesquisa, será adotada a definição de falência formal, devido à disponibilidade de informações junto aos órgãos oficiais especialmente a Junta Comercial do Estado do Rio Grande do Sul, da qual a amostra da população será retirada.

\section{METODOLOGIA}

Para apresentar o conceito das MPE, tradicionalmente, são utilizados vários parâmetros, entre eles: mão de obra empregada, capital investido, faturamento, quantidade produzida etc. Neste estudo considerouse o tipo jurídico e o faturamento, pois as empresas, extintas, pesquisadas são cadastradas na Junta Comercial, órgão responsável pelo registro de atividades ligadas a sociedades empresariais.

Como o foco desta pesquisa concentra-se nas causas que ocasionam a mortalidade precoce de microempresas, buscou-se elaborar uma revisão teórica sobre o assunto que proporcionasse subsídios para a composição de um conjunto de fatores relacionados ao tema, que compusessem o instrumento de pesquisa. Em seguida, efetuou-se um levantamento com empresas que atuaram no comércio e serviço na região centro do Rio Grande do Sul, que são cadastradas na Junta Comercial do RS e que iniciaram suas atividades ao 
longo do ano de 2010 e por motivos que serão expostos nos resultados extinguiram-se até o ano de 2013, ou seja, não ultrapassaram a fase de maturidade.

Esta pesquisa trata-se de uma pesquisa de campo que foi realizada nos meses de fevereiro e março de 2014. Quanto à amostra, buscou-se elaborar um estudo representativo, para tanto, calculou-se o tamanho da amostra com base nas fórmulas estatísticas que permitam generalizar os resultados obtidos para toda a população. Considerando a intenção de estimar algumas proporções da população finita na análise descritiva, utilizou-se um erro amostral de 5\%, nível de confiança de 95\%, uma população no total de 2146 pessoas, assim obteve-se o tamanho da amostra de 326 empreendedores a serem pesquisados.

A pesquisa desenvolveu-se em nove etapas como pode ser observado na Figura 3.

Figura 3: Etapas do processo metodológico

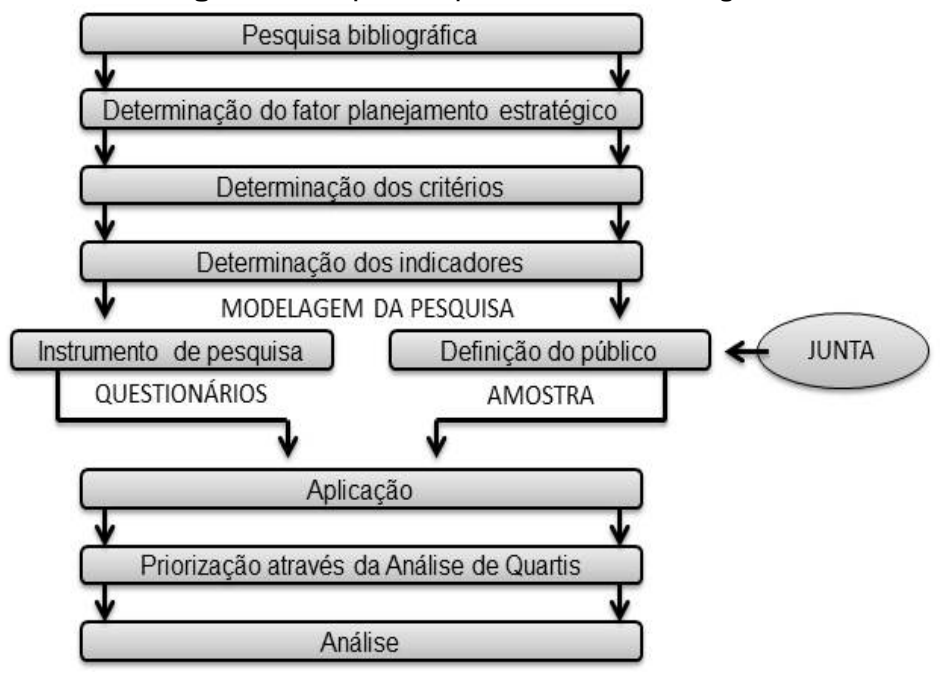

Fonte: Elaborada pelos autores

É de fundamental importância o levantamento bibliográfico na determinação do fator planejamento estratégico, pois como foi exposto nesse referencial, segundo pesquisas dos autores Grapeggia et al., (2011); Ferreira et al., (2012); Dutra, (2002) e Bedê, (2004), mostram as principais causas da mortalidade de microempresas em fase inicial. Logo em seguida foram levantados os critérios que conforme Wright, Kroll e Parnell (2000); Fernandes e Berton (2006) as principais estratégias funcionais normalmente elaboradas são as relacionadas às áreas de produção, marketing, finanças, recursos humanos, qualidade e tecnologia.

Submerso a estas áreas estão às capacidades de determinação de diversas estratégias competitivas que envolvidas ao planejamento estratégico qualificam e quantificam em resultados positivos os recursos elencados (BEETHLEM, 2002; KICH e PEREIRA, 2011).

Em sequência determinaram-se indicadores que avaliassem como os empreendedores remetiam-se as estratégias de cada critério. Os indicadores foram definidos como sendo fatores de sucesso para o alcance da estratégia competitiva da organização, da estratégia geral do negócio, bem como do objetivo acerca de cada área de acordo com Beethlem, (2002); Kich e Pereira, (2011); Wright, Kroll e Parnell (2000); Fenandes e Berton (2006); Bernardi, (2011); Kplan e Norton, (2004); Thompson Jr e Strickland III (2002) que citam quais os principais pontos, a ser seguidos no intuito de obter um planejamento estratégico que atinja a toda a organização. Na Figura 4 é possível observar estes indicadores e sua respectiva área.

Figura 4: Estrutura hierárquica de apoio para a montagem do instrumento de pesquisa. 
FATOR

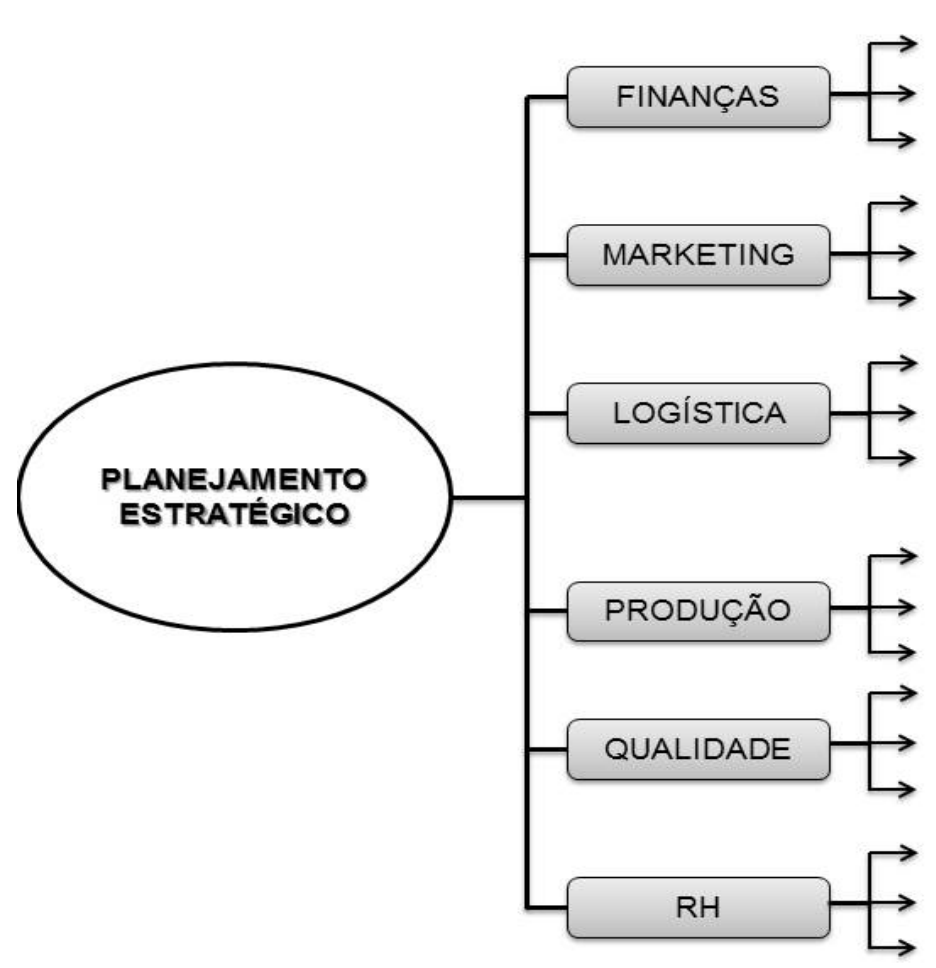

INDICADORES

Índice de inadimplência;

Tarifas bancárias ;

Capital de terceiros.

Pesquisa de satisfação ;

Endomarketing;

Ações de marketing.

Prazos de entrega;

Custos de frete;

Entrega.

Produtividade;

Estoque;

Demanda.

Fornecedores;

Mapeamento de processos;

Ferramentas de controle.

Recrutamento e seleção ;

Plano de carreira;

Treinamento e desenvolvimento.

Fonte: Elaborada pelos autores com base em Grapeggia et al., (2011); Ferreira et al., (2012); Dutra, (2002) e Bedê, (2004); Beethlem, (2002); Kich e Pereira, (2011); Wright, Kroll e Parnell (2000); Fenandes e Berton (2006); Bernardi, (2011); Kplan e Norton, (2004); Thompson Jr e Strickland III (2002).

Assim a partir desta definição elaborou-se o instrumento de pesquisa que contém 22 questões, onde quatro remetiam a algumas características do empreendimento e do empreendedor e as demais perguntas eram relacionadas aos indicadores expostos, para estas perguntas foram utilizadas escala Likert de 5 pontos cada, onde os pontos variam de 1 para "discordo totalmente" e 5 para "concordo totalmente".

Por fim após todos os instrumentos de pesquisa respondidos e analisados foi realizada uma ordem de priorização dos critérios ponderados, por meio da Análise de Quartis, que, comparada a outros métodos já consolidados na literatura, tais como o Importance Performance Analysis (IPA), apresenta como vantagem a não necessidade de coletar a importância referente a cada item do questionário. Este fator auxilia no enxugamento da pesquisa, facilitando assim o momento dos questionados responderem o instrumento o que consequentemente agrega para pesquisas com grandes amostras, caso deste estudo (FREITAS, MANHÃES e COZENDEY, 2006). 


\section{ANÁLISE DOS RESULTADOS}

A amostra de 326 empresários, a qual resultou na aplicação do questionário, especificado na metodologia, junto aos empreendedores das microempresas que se extinguiram obteve 282 respondentes, assim, em duas etapas, serão apresentados os resultados obtidos, primeiramente será exposto o perfil do microempreendedor e de seu empreendimento e posteriormente as principais causas, focadas no planejamento estratégico, que levaram ao encerramento das atividades.

\section{Descrição dos microempreendores entrevistados e de seus microempreendimentos}

Primeiramente concluiu-se que $62,77 \%$ dos 282 entrevistados são do sexo masculino. Já em relação ao grau de escolaridade verificou-se que $87,9 \%$ dos 282 pesquisados possuem no mínimo segundo grau completo, destes, $37,1 \%$ alegam ter curso superior completo e $31,5 \%$ dos graduados possuem pósgraduação, sendo assim apenas 29 microempreendedores continuaram qualificando-se ao final da faculdade.

No que diz respeito a quantos funcionários mantinham vinculo empregatício com carteira assinada, registrou-se que estas organizações trabalhavam com 2 a 6 empregados, sendo que, a maioria $40,8 \%$ contava com 3 mãos de obra apenas. Quanto ao setor de atuação das microempresas foram pesquisadas somente as que se concentravam em desempenhar suas atividades na área do comércio $(35,5 \%)$ e de serviços $(64,5 \%)$.

Indagou-se sobre os principais motivos que levaram a abertura do negócio, obtendo como respostas as seguintes contribuições:

- Identificação de oportunidade $(25,5 \%)$

- Desejo de ter um negócio próprio (17\%)

- Ocorrência simultânea dos dois motivos anteriores $(36,7 \%)$

- Desejo de aumentar a renda e melhorar de vida $(14,9 \%)$

O restante $(4,9 \%)$ apontou outros motivos como: o ajuste da empresa familiar e a adequação a clientes e a legislação.

\section{Descrição das principais causas que levaram ao encerramento das atividades}

Conforme consta na figura XX levantaram-se os três principais indicadores, remetentes ao planejamento estratégico, de cada área necessária para uma boa gestão empresarial. Cada indicador foi avaliado de acordo com uma escala Likert de 5 pontos, onde indiretamente os pontos crescem de forma positiva, ou seja, quanto maior a pontuação maior a atenção dada ao indicador e consequentemente a área.

Para uma gestão estratégica de finanças foi considerado se o índice de inadimplência da organização era devidamente acompanhado, mantendo assim este estável, outro indicador levantado remetia à realização de pesquisas a fim de estimar uma unidade bancária com melhores taxas para se trabalhar, e por fim se a dependência de capital de terceiros era considerada baixa.

Todos estes quesitos fazem com que a empresa prospere no sentido de obter seus lucros, a fim de conquistar a maior fatia possível de mercado, além disso, a gestão estratégica de finanças é que disponibiliza 
boa parte das informações gerenciais necessárias para avaliação do todo (BRIGHAN e EHRHARDT, 2006). Desta maneira a Figura 5 expressa que o indicador mais defasado dentre os três é a dependência de capital de terceiros seguido da falta de realização de pesquisas para obter menores taxas.

Figura 05: Análise da área de Finanças (A1)

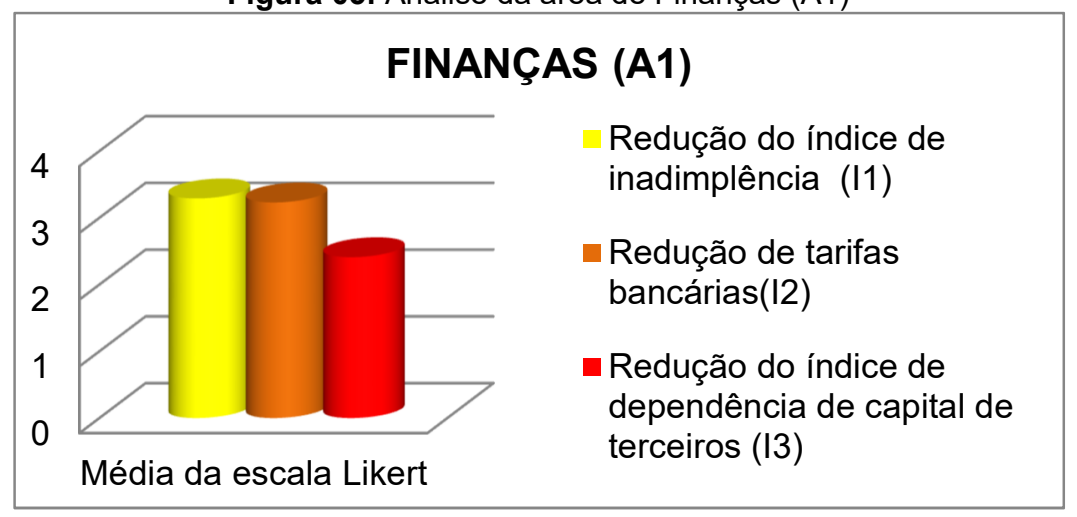

Fonte: Elaborada pelos autores

Isto pode indicar que muitos empreendedores ao começarem suas atividades não possuem capital suficiente para cobrir o investimento inicial, buscando então auxilio financeiro fora.

Alguns economistas como Rozo (2001), não condenam a atitude, afirmando que a utilização de capital de terceiros permite ao empreendedor uma ampliação do negócio em tempo acelerado, comparado ao uso de recursos próprios, porém como este indicador precede pelo 12, o qual enfatiza a falta de informações que possam levar o empresário a menores taxas, essa sequência de atitudes veem a enfraquecer o negócio.

$\mathrm{Na}$ área relacionada ao marketing estratégico levantou-se a realização de pesquisas de satisfação juntamente ao cliente, para assim controlar a qualidade do produto e/ou serviço, além de identificar oportunidades de melhorias, o uso do endomarketing, pratica esta que segundo Brum (2000) é um ciclo motivacional interno que tem por objetivo encantar e comprometer os colaboradores na busca de um resultado em comum: o aumento e qualidade da produção, além da conquista de um clima organizacional saudável e o indicador de controle das práticas de marketing. Assim a Figura 6 ilustra os resultados obtidos neste contexto.

Figura 6: Análise da área de Marketing (A2)

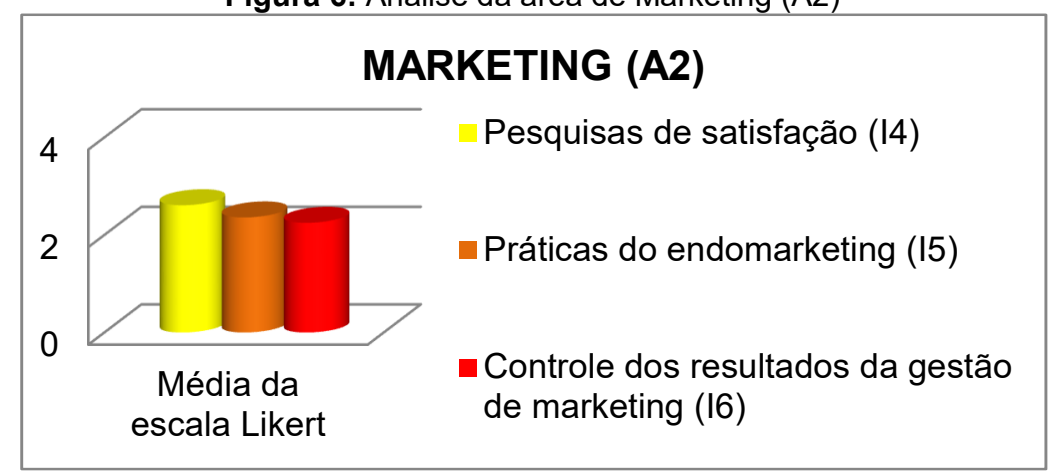

Fonte: Elaborada pelos autores 
Observa-se que o controle de resultados das ações de marketing é o indicador menos praticado, em seguida o quesito endomarketing. Deste modo Lima e Carvalho (2011), condicionam que muitas vezes exercer atividades de marketing demandam tempo e dinheiro, assim se estas não forem devidamente fiscalizadas a fim de mensurar seus resultados, contrapondo com os investimentos, acabam por não agregarem o conhecimento de mercado necessário e ainda se corre o risco de desperdiçar investimentos, tempo e principalmente oportunidades.

A terceira gestão estratégica abordada remete à logística, onde itens selecionados para análise foram inerentes ao cumprimento dos prazos de entrega, ao controle de fatores causadores de custos mais elevados de entrega e se os prazos de entrega eram considerados ideais pelos clientes. Na Figura 7 é possível verificar a média de afirmações de cada ponto levantado.

Figura 7: Análise da área de Logística (A3)

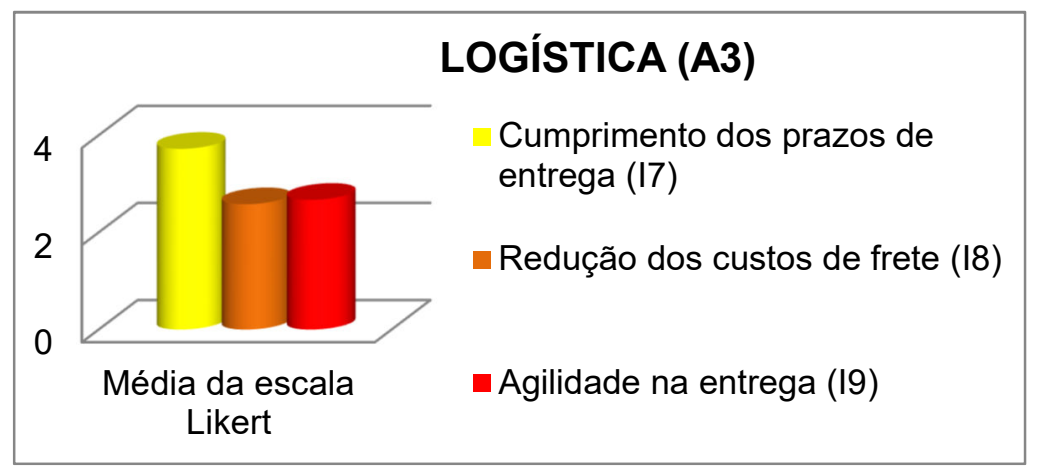

Fonte: Elaborada pelos autores

As intempéries que fazem o custo de transporte aumentar se precavidas, analisadas e controladas garantem a satisfação do cliente e um menor custo para a empresa, pois entregas programadas através da realização dos relatórios, o qual facilita a comunicação intersetorial dentro da organização, por exemplo, tende a esta garantia. Este indicador segundo a pesquisa foi o que menos se atendeu pelas microempresas extintas.

O campo produção é entendido por Freire (2009) como a produção do produto/objeto em si, ou pela concretização/ato do serviço oferecido. Deste modo elencou-se como indicadores estratégicos para a análise deste critério a existência do controle de produtividade, para evitar assim o desperdício de tempo, pessoas e material, o controle de estoque (produtos e insumos) e a realização da previsão de demanda, a fim de estimar a produção em determinado período de tempo. Na Figura 8 expõem-se os resultados encontrados.

Figura 8: Análise da área de Produção (A4)

Controle de produtividade (I10)
Controle de entrade e saída de
produtos e ensumos (I11)
Controle de demanda (I12)

Fonte: Elaborada pelos autores 
O indicador, de acordo com os microempresários, que apresentou mais deficiência foi a previsão de demanda, o que pode sugerir que não existia um planejamento adequado em suas operações, pois esta prática é considerada o ponto de partida para uma programação de produção. O quesito referente ao controle de produtos e insumo foi o segundo indicador mais vil onde a falta de inspeção deste leva à desperdícios acarretando danos ao capital de giro da organização.

A qualidade define-se como uma área que por si só é estratégica, pois é fornada pelos processos de planejamento, controle e melhoria (PALADINI, 2010). Assim pensando no contexto microempresa foram levantados três quesitos para ponderação deste setor, primeiramente indagou-se sobre a questão da utilização de critérios para seleção de fornecedores, posteriormente se os processos da empresa eram mapeados, e por fim se eram utilizadas ferramentas de controle para a análise e melhoria e solução de problemas que eventualmente são encontrados e interferem no bom desempenho dos processos.

A Figura 9 revela que o principal ponto em descuido dos microempreendedores neste critério é a falta de prevalecer-se das ferramentas de processos para a correção de inconformidades. Essa ausência de cultura reflete na tomada de decisão baseada no "achismo", o qual não se embasa nas reais causas dos acontecimentos, surgindo assim resultados inesperados, prejudicando todo o planejamento da organização.

Figura 9: Análise da área de Qualidade (A5)

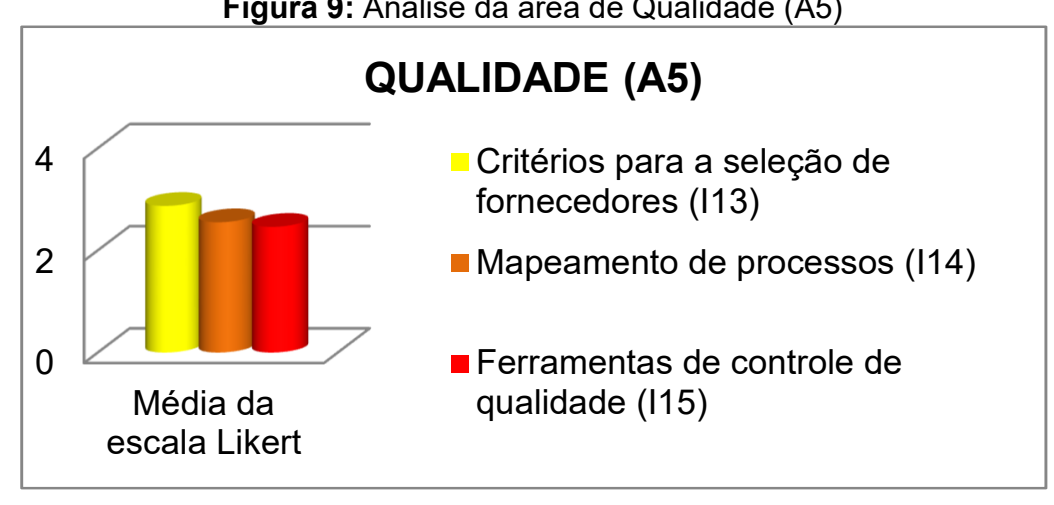

Fonte: Elaborado pelos autores

Por fim os indicadores levantados para a área de recursos humanos foram o alinhamento das estratégias organizacionais ao recrutamento e seleção, a estruturação de um plano de carreira para os colaboradores e a adequação do treinamento e desenvolvimento dos funcionários com seus cargos. Analisouse que o 116 apresentou pior desempenho dentre os quesitos observados, assim sem esse alinhamento a empresa não conquistará talentos capazes de compreender sistematicamente as principais prioridades e processos que levam o negócio a criar seu valor (Figura 10). 
Figura 10: Análise da área de Recursos Humanos (A6)

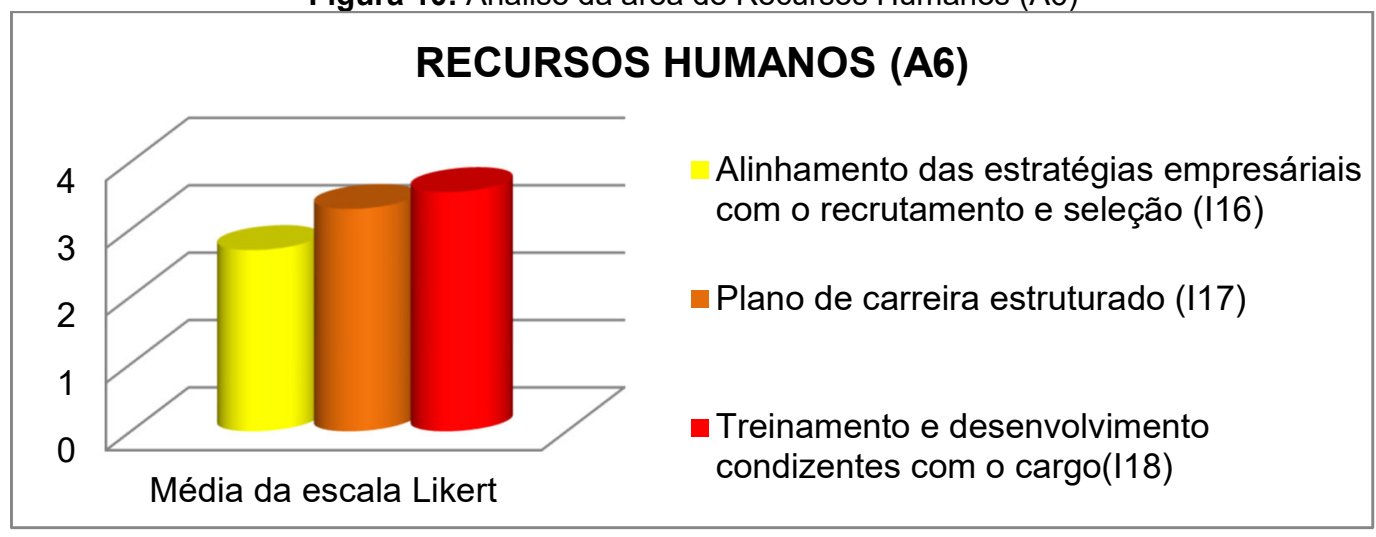

Fonte: Elaborado pelos autores

O segundo item mais prejudicado nesta área remete ao plano de carreira, indicando primordialmente que sem este processo estruturado qualquer funcionário tende a perder seu foco perante os objetivos da organização.

Após o diagnóstico das áreas, separadamente, aplicou-se a Análise de Quartis para identificar primeiramente a área mais omissa por parte dos microempreendedores conforme Tabela 1, posteriormente usou-se desta mesma técnica para perceber aqueles indicadores estratégicos que mais comprometem o sucesso das microempresas.

Tabela 1: Priorização das Áreas através da Análise Quartis

\begin{tabular}{|c|c|c|c|c|c|c|}
\hline \multicolumn{7}{|c|}{ Classificação das Áreas } \\
\hline $\mathbf{A}_{2}$ & A5 & $\overline{\mathbf{A}_{1}}$ & & $A_{3}$ & $\mathbf{A}_{4}$ & $\mathbf{A}_{6}$ \\
\hline 2,41 & 2,63 & 2,98 & & 2,99 & 3 & 3,27 \\
\hline & 19 Quartil $=2,63$ & & 20 Qua & & Ruartil $=$ & \\
\hline Prioridades: & Crítica & & Alta & & ada & Baixa \\
\hline
\end{tabular}

Fonte: Elaborada pelos autores

A área de marketing revelou-se como um critério pouco desenvolvido por parte dos microempreendedores. Como a pesquisa foi aplicada a empresários que já findaram suas atividades por causas desconhecidas, leva-se a considerar que esta área é importante no contexto empresarial. Acerca disso se pode afirmar que o planejamento estratégico de marketing é estimado como um fator ideal para se ter sucesso.

O foco de uma empresa é voltado ao cliente, desta forma o marketing possui as principais ferramentas capazes de perceber as necessidades, desejos e interesses do público alvo, e para isso são necessárias ações que não se limitem em apenas desvendar estes pontos, mas sim fazê-los com sejam atendidos e melhorados constantemente através de diferenciais.

Em sequência outra área que mediante a pesquisa apresentou baixo acompanhamento foi a qualidade estratégica, formando o primeiro quartil da análise. Deming (1198) e Juran (1992) já afirmavam que com qualidade se tem produtividade e consequentemente competitividade, para tanto, manter estes três potenciais assíduos dentro da organização é necessário aprimoramento constante.

Já na análise referente aos indicadores levantados observa-se, segundo Tabela 2, que os que se encontram no campo de criticidade são: 16, 15, I3 e I15. 
Tabela 2: Priorização dos Indicadores através da Análise Quartis

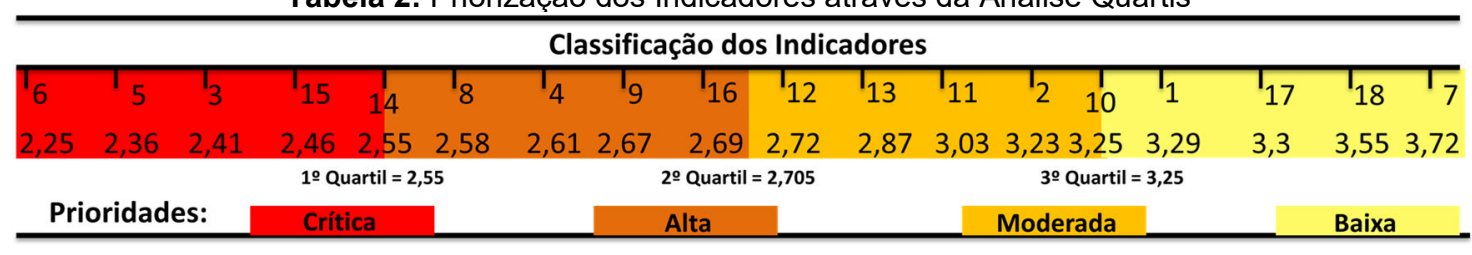

Fonte: Elaborada pelos autores

Os dois primeiros indicadores remetem à área de marketing, o 13 à área de finanças e o 115 à área da qualidade; o quesito mais crítico faz referência ao controle dos resultados obtidos com o uso das práticas de marketing, podendo indicar que não eram realizadas práticas ou que estas não eram realmente mensuradas. Esse resultado abre possibilidades para trabalhos que visem subsidiar a área.

O segundo item faz ênfase ao endomarketing, sua má classificação indica a não cultura de exercer esta técnica que tanto auxilia nos planos e gestão de abordagem aos empregados, visando assim a máxima qualidade dos produtos e serviços.

O I3 abrange a alta dependência de capital de terceiros, e o I15 à falta de uso das tantas ferramentas que a qualidade oferece com o intuito de analisar fatos, para então auxiliar na tomada de decisão mais indicada baseada em dados visando sempre a otimização dos processos operacionais das empresas (AMBROZEWICZ, 2003). Como dito anteriormente isto sugere que os empreendedores buscavam tomar decisões na base do "achismo" comprometendo o planejamento do negócio.

\section{CONCLUSÃO}

Os resultados da pesquisa apontam que atender a todas as áreas, de forma a comprometê-las estrategicamente é vital para uma organização, uma visão sistêmica faz com que todas estas se integrem e auxiliem no planejamento e comunicação inter setorial. Porém a área que apresentou o maior índice de descuido foi a área inerente ao planejamento estratégico de marketing, indicando que estas empresas devem boa parte de sua extinção à negligência perante as práticas alçadas pelo marketing.

Dentre os indicadores lançados como estratégicos na área de marketing o que obteve menor percentual de execução foi dado ao controle dos resultados da gestão da área, seguido da não utilização das práticas do endomarketing. No entanto é preciso ampliar o estudo para incorporar outros indicadores e verificar mais afundo as causas que levaram a comprometer a eficiência de cada um deles.

A complexidade acerca dos fatores que condicionam o sucesso e o fracasso das organizações é bastante discutida, muitos estudos não levam em consideração motivos que não remetem verdadeiramente ao insucesso, quando o negócio é extinto, como, por exemplo, o fechamento devido ao repasse da empresa a um terceiro ou até mesmo o fechamento em consequência da abertura de um outro negócio.

Desta maneira, variáveis como estas foram devidamente consideradas, principalmente pelo fato de se ter levantado a população e consequentemente a amostra juntamente com um órgão formal.

Este estudo teve como intuito auxiliar microempreendedores ativos a não cometerem as mesmas falhas, podendo também assim dizer que o quesito planejamento estratégico de marketing é um fator que se bem dirigido, acompanhado e mensurado, juntamente com os demais, poderá vir a levar uma microempresa ao sucesso. 


\section{REFERÊNCIAS}

AMBROZEWICZ, Paulo Henrique Laporte. Qualidade na prática: conceitos e ferramentas. Curitiba: Serviço Nacional de Aprendizagem Industrial. Departamento Regional do Paraná, 2003.

BANCO NACIONAL DE DESENVOLVIMENTO ECONOMICO E SOCIAL Carta Circular n 64/2002. Rio de Janeiro, 14 de outubro de 2002. Disponível em < http://www.bndes.gov.br/produtos/download/02cc64.pdf> Acesso em : 07 fev 2014.

BARROS, A. Gestão Estratégica nas Pequenas e Médias Empresas. Rio de Janeiro: Editora Ciência Moderna Ltda., 2005.

BATISTA, F. B. et al. Uma investigação acerca da mortalidade das microempresas e empresas de pequeno porte da cidade de Sousa, PB. Reunir. Revista de Administração, Contabilidade e Sustentabilidade, v. 2, n.1, p. 56-71, jan/abr 2012.

BEDÊ, M. A. Sobrevivência e mortalidade de empresas paulistas de 1 a 5 anos. São Paulo: Sebrae, 2004.

BERNARDI, L. A. Manual de empreendedorismo e gestão: fundamentos, estratégias e dinâmicas. São Paulo: Ed. Atlas, 2011.

BETHLEM, A. Estratégia empresarial: conceitos, processo e administração estratégica. São Paulo: Atlas, 2002.

BRIGHAM, Eugene F. EHRHARDT, Michael C. Administração financeira. 10 ed. São Paulo: Pioneira Thomson Learning, 2006.

BRUM, A. M. Um olhar sobre o marketing interno. 3 ed. Porto Alegre: L\&PM, 2000.

COCHRAN, A. B. Small Business Mortality Rates: A Review of the Literature. Journal of Small Business Management, v. 19 , n. 4, p. 50-59, 1981.

DEMING, W.E. Os 14 pontos da Qualidade. Rio de Janeiro. Publicações Diversas,1998.

DUTRA, I. de S. O perfil empreendedor e a mortalidade de micro e pequenas empresas londrinenses. 2002. Dissertação (Mestrado em Administração) - Universidade Estadual de Londrina, Londrina, 2002.

FERNANDES, B. H.; BRTON, L. H. Administração estratégica: da competência empreendedora à avaliação de desempenho. São Paulo: Saraiva, 2006.

FERREIRA, L. F et al. Análise quantitativa sobre a mortalidade precoce de micro e pequenas empresas da cidade de São Paulo. Revista Gestão \& Produção, Universidade de São Carlos/SP, v. 19, n. 4, p. 811-823, dez 2012.

FISCHER, A; NODARI, T; FEGER, J. Empreendedorismo: algumas reflexões quanto as características. . Revista Gestão \& Produção, Universidade de São Carlos/SP, v. 7, n. 1, p. 39-52, jan/jun 2008.

FREIRE, Alexandre. A arte de gerenciar serviços: quando o espírito humano supera a ciência na gestão. São Paulo: Strong Consultoria Educacional, 2009.

GRAPEGGIA M. et al. Fatores condicionantes de sucesso e/ou mortalidade de micro e pequenas empresas em Santa Catarina. Revista Produção, Escola Politécnica da Universidade de São Paulo, v. 21 n. 3. São Paulo, Jul/Set. 2011.

IBGE (2013), "Demografia das Empresas - 2011". Rio de Janeiro, 2013. Disponível em: <http://biblioteca.ibge.gov.br/visualizacao/livros/liv65422.pdf>. Acesso em 12 fev. 2014.

JURAN, J. M. Juran planejando para a qualidade. Tradução de João Mário Csillag, Cláudio Csillag. 3. ed. São Paulo: Pioneira, 1992 . 394 p. Título original: Juran on planning for quality.

$\mathrm{KICH}$, J. I.; PEREIRA, M. F. A influência da liderança, cultura e comunicação organizacional no processo de implantação do planejamento estratégico. Cadernos EBAPE, Fundação Getúlio Vargas. V. 9, n. 4, p. 1045-1065, jan/dez, 2011.

KOTESKI, M. A. As micro e pequenas empresas no contexto econômico braาsileiro. Revista Fae Business, Curitiba, n. 8 , p. 16-18, maio 2004

KPLAN, R. S; NORTON, D. P. Mapas estratégicos: convertendo ativos intangíveis em resultados tangíveis. Rio de Janeiro: Elsevier, 2004.

LIMA, G. B.; CARVALHO, D. T. Plano Estratégico de Marketing: Proposta de uma Análise Teórica. Revista Brasileira de Marketing, v. 10, n. 2, p. 163-187, 2011.

MACHADO, H. P. V.; ESPINHA, P. G. Reflexões sobre as dimensões do fracasso e mortalidade de pequenas empresas. Revista Capital Científico, v. 3, n. 1, p. 51-64, jan./dez. 2005.

OLIVEIRA, D. de P. R. de. Planejamento Estratégico: Conceitos, Metodologia, Prática. São Paulo: Atlas, 2002

PALADINI, E. P. Gestão da Qualidade: teoria e prática; $2^{a}$ Ed. São Paulo: Atlas, 2010.

ROZO, J. D. Novos projetos: o que valoriza mais a empresa, recursos próprios ou de terceiros? qual a proporção ótima? Revista contabilidade \& finanças, v.16, n. 27, p. 78-88, set/dez 2001. 
SEBRAE; DEPARTAMENTO INTERSINDICAL DE ESTATÍSTICA E ESTUDOS SOCIOECONÔMICOS - DIEESE. Anuário do trabalho na micro e pequena empresa: 2011-2012. São Paulo, 2012.

Secretaria da recita federal. SIMPLES - Sistema Integrado de Pagamentos de Impostos e Contribuições das Microempresas e Empresas de Pequeno Porte, http://www.receita.fazenda.gov.br/legislacao/legisassunto/simples.htm acesso 07 fev 2014

Senado Federal Secretaria Especial de editoração e publicações subsecretaria de edições técnicas - Estatuto da Microempresa. http://www2.senado.leg.br/bdsf/bitstream/handle/id/70314/662418.pdf?sequence=2 . acesso $07 \mathrm{fev}$

SERASA EXPERIAN (2013), "Indicador Serasa Experian 31/07/2013". São Paulo, 2013. Disponível em: <http://www.serasaexperian.com.br/release/noticias/2013/noticia_01290.htm>. Acesso em 12 fev. 2014.

SHANE, S.; LOCKE, E.; COLLINS, C. J. Entrepreneurial motivation. Human Resource Management Review, v. 13, n. 2 , p. 257-279, 2003.

STEL, A. V.; CARREE, M.; THURIK, R. The effect of entrepreneurial activity on national economic growth. Small Business Economics, v. 24, p.311-321, 2005.

THOMPSON JR, A. A.; STRICKLAND iii, A. J. Planejamento estratégico: elaboração, implementação e execução. São Paulo: Pioneira, 2002.

TRINDADE, M.B. et al. Gestão do capital de giro em micro e pequenas empresas. Revista de administração, contabilidade e economia, Universidade do Oeste de Santa Catarina/SC, v. 9, n. 1-2, p. 231-250, jan/dez 2010.

WRIGHT, P. L.; KROLL, M. J.; PARNELL, J. Administração estratégica: conceitos. São Paulo: Atlas, 2000. 